\title{
PRACTICES OF CLINICAL EXAMINATION OF HEART FAILURE PATIENTS IN PRIMARY HEALTH CARE
}

\author{
Aino Laukkanen ${ }^{1}$, Markku Ikäheimo ${ }^{3}$, Heikki Luukinen² \\ 1Department of Public Health Science and General Practice, University of Oulu, Oulu, Finland \\ 2Unit of General Practice, Oulu University Hospital, Oulu, Finland \\ ${ }^{3}$ Department of Internal Medicine, Oulu University Hospital, Oulu, Finland
}

\begin{abstract}
SUMMARY
The aim of this cross-sectional cohort study was to examine practices of clinical examination of heart failure patients in three primary health care regions in northern Finland. Altogether, 825 randomly selected heart failure patients aged 45 years or older, who had special reimbursement for drugs for the treatment of heart failure, were included. Main outcome measures were the frequency of medical visits and the mode of clinical examinations during control visits and symptomatic visits due to heart failure made by general practitioners.

The prevalence of heart failure was $2 \%$ among those aged $45-75$ years and $18 \%$ among the older ones. No differences existed in the incidence of all medical visits made as a result of heart failure, between the regions. ECG recordings, auscultation of the heart and lungs, measurements of blood pressure and recordings of ankle swelling were carried out in $72 \%, 79 \%, 85 \%, 90 \%$ and $59 \%$ of cases of control visits, and in $78 \%, 63 \%$, $79 \%, 77 \%$ and $49 \%$ of cases in symptomatic visits, respectively. Chest X-ray examinations and recording of liver size were seldom carried out: $16 \%$ and $12 \%$ in control visits, and $19 \%$ and $11 \%$ in symptomatic visits, respectively. Important prognostic markers of heart failure were recorded even more rarely: jugular venous pressure, in $1 \%$ of control visits and $3 \%$ of symptomatic visits and the third heart sound not at all. NYHA grading had been carried out in $8 \%$ and echocardiography in $13 \%$ of cases.

The prevalence of heart failure was higher than in many clinical studies, suggesting high number of false positive heart failure diagnoses made in primary health care. Some clinical examinations of significant prognostic value in heart failure are underused by general practitioners. Therefore, further education among general practitioners is needed to improve the practices of clinical examination in heart failure patients.
\end{abstract}

Key words: heart failure, clinical examination, primary health care

Address for correspondence: Aino Laukkanen, Department of Public Health Science and General Practice, University of Oulu, Aapistie 1, SF-90220 Oulu, Finland. E-mail: aino.laukkanen@oulu.fi

\section{INTRODUCTION}

Heart failure (HF) is the most common reason for hospitalization in older adults (1) and the 5-year death rate has been more than $50 \%$ over the last $20-40$ years. Recent advances in treatment have reduced mortality to 5 -year death rates of $25 \%$ in men and $38 \%$ in women (2). The prevalence of heart failure is about $1.5 \%$, increasing steeply with age (3) and reaching $6.8 \%, 10 \%$ and $8.1 \%$ among those aged 75,80 and 85 years, respectively. Annually, 1.85 new HF cases become manifest in a population of 1,000 persons (4), with men [4.1/1,000 person-years (PY)] being affected more often than women $(1.6 / 1,000$ PY) (5).

A large European study of the diagnosis and treatment of heart failure (6) provides an international comparison of primary-care physicians' knowledge and attitudes to the management and treatment of the HF patients. However, the number of false positive HF diagnoses made by general practitioners (GPs) is great (7), suggesting that clinical examinations carried out by GPs among HF patients may be unsatisfactory. Therefore, we conducted a register-based study, aimed at examining the frequency of visits and the mode of clinical examinations carried out by GPs among HF patients.

\section{METHODS}

\section{Study Population}

The material for this study was collected from the medical records of three different primary health care regions in northern Finland: 1. the city of Oulu, 2. the city of Kemi, the city of Tornio and the municipality of Keminmaa, 3. the city of Rovaniemi and the rural community of Rovaniemi. The respective terms Oulu, Kemi and Rovaniemi are used to represent these regions.

According to the register of the Social Insurance Institution, 5,552 residents aged 45 or older and living in these primary health care regions at the beginning of the study, May 9, 1997, had special reimbursement for drugs for the treatment of HF.

Every fifth HF case in Oulu ( $N=574)$, every third one in Kemi ( $\mathrm{N}=462)$ and every third one in Rovaniemi $(\mathrm{N}=432)$ were randomly selected for the study. The data were collected by one of the researchers (AL) from the medical records for the time period lasting from June 1 to December 31, 1997. Those who received treatment for $\mathrm{HF}$ at Central Hospital $(\mathrm{N}=235)$ or in the private sector $(\mathrm{N}=291)$, and those who lived in long-term institutional care $(\mathrm{N}=26)$, or who had no medical treatment for 
Table 1. The incidence of medical visits of HF patients to GPs and internists (N/1000 person years, 95\% Cl) during two years of follow-up in three different geographical regions

\begin{tabular}{|l|c|c|c|c|c|c|}
\hline & \multicolumn{2}{|c|}{$\begin{array}{c}\text { Oulu } \\
\text { N = 352 }\end{array}$} & \multicolumn{2}{c|}{$\begin{array}{c}\text { Kemi } \\
\text { N=221 }\end{array}$} & \multicolumn{2}{c|}{ Rovaniemi } \\
N $=252$
\end{tabular}

heart disease during the two previous years $(\mathrm{N}=51)$, or who died between the date of randomization and examination of medical records $(\mathrm{N}=28)$, or who had moved or whose medical records could not be traced $(\mathrm{N}=12)$, were excluded. Accordingly, the final study population included a total of 825 persons ( $56 \%$ of the 1,468 originally selected), 352 in Oulu ( $61 \%$ of the original number for the region), 221 in Kemi (48\%) and 252 in Rovaniemi (58\%).

\section{Methods}

All visits to health centres for treatment of HF made two years prior to the examination day were recorded. The number of all 'symptomatic visits' (SVs) as a result of cardiac symptoms (chest pain, arrhythmia, dyspnoea, hypertension or peripheral oedema) was recorded and the nature of the last one was examined according to a structured form. Control visits (CVs) were defined as ones previously planned in connection with treatment of HF. The nature of the last two CVs was examined.

The number of visits to internists for treatment of HF, taking place in hospital or privately, were recorded.

The following tests and examinations were recorded: ECG, chest X-ray, details of clinical examination (auscultation of heart and lungs, evaluation of liver size, ankle swelling and jugular venous pressure), measurement of blood pressure and assessment of NYHA (New York Heart Association) functional class. The result of echocardiography (ECHO) was also recorded.

\section{Statistical Analyses}

The incidence rates of medical visits per 1000 person years (PY) and their 95\% confidence intervals (95\% CIs) derived from Poisson distribution were determined.

Differences in examination practices between the study regions were examined using the $\chi^{2}$ test or the Kruskal-Wallis test. Statistical significance was set at $\mathrm{p}<0.05$.

The computation was carried out using SAS Statistical Software on a SUN/UNIX mainframe computer (Sun Microsystems, Inc., Palo Alto, CA).

\section{RESULTS}

\section{Prevalence of $\mathbf{H F}$}

In these three primary health care regions a total of 5,552 (7.2\%) people had special reimbursement in regard to drugs for the treatment of HF. In Oulu the prevalence was $7.9 \%$, in Kemi $6.5 \%$ and in Rovaniemi $6.6 \%$. Among those aged $45-75$ years the prevalence was $2 \%$ and among the older ones $18 \%$, respectively.

\section{Background Data}

There were 241 (29\%) men and 584 (71\%) women with HF. Men totalled $118(34 \%)$ in Oulu, $55(25 \%)$ in Kemi and $68(27 \%)$ in Rovaniemi $\left(\chi^{2}=5.767\right.$, d.f. $\left.=2, \mathrm{p}=0.056\right)$.

The mean age of the participants was 74.8 (SD 8.3) years in Oulu (range 46 to 95 years), 77.0 (8.2) years in Kemi (range 50 to 96 years) and 75.8 (8.2) years in Rovaniemi (range 50 to 97 years) (Kruskal-Wallis, $\mathrm{p}=0.048$ ).

Data on the duration and aetiology of HF were available in 206 $(25 \%)$ subjects. The diagnosis of HF had been made on average 12.7 years previously (SD 6.6 years). Factors associated with HF were hypertension (48\%), ischaemic heart disease (81\%), chronic atrial fibrillation $(10 \%)$, other arrhythmia (11\%) and cardiomyopathy $(3 \%)$.

\section{Frequency of Medical Visits because of HF}

The frequencies of medical visits to general practitioners and internists in two- year period in the three study regions are shown in Table 1. No differences existed in the incidence of all medical visits connected to HF between the regions. The incidence of visits to health centres was greater in Rovaniemi than in Oulu. Control visits occurred more frequently in Rovaniemi than in Oulu and Kemi. The incidence of SVs was higher in Kemi than in Oulu and Rovaniemi.

The mean number of medical visits to GPs in the two-year period was 1.8 (SD 1.6).

\section{Contents of the Clinical Examination among HF Patients}

The contents of $622 \mathrm{CVs}$ and $196 \mathrm{SVs}$ were analysed. Some patients may have paid both kinds of visit, and the contents of the clinical examinations are shown in Table 2.

Table 2. Contents of clinical examination among HF patients

\begin{tabular}{|l|c|c|c|c|}
\hline & \multicolumn{2}{|c|}{$\begin{array}{c}\text { Control visits } \\
\text { (N=622) }\end{array}$} & \multicolumn{2}{c|}{$\begin{array}{c}\text { Symptomatic visits } \\
(\mathrm{N}=196)\end{array}$} \\
\hline & $\mathrm{N}$ & $\%$ & $\mathrm{~N}$ & $\%$ \\
\hline ECG & 449 & 72 & 153 & 78 \\
\hline Chest-X-ray & 100 & 16 & 37 & 19 \\
\hline Heart rate & 516 & 83 & 150 & 77 \\
\hline Heart sounds & 491 & 79 & 124 & 63 \\
\hline Blood pressure & 562 & 90 & 150 & 77 \\
\hline $\begin{array}{l}\text { Pulmonary } \\
\text { auscultation }\end{array}$ & 529 & 85 & 155 & 79 \\
\hline Liver size & 75 & 12 & 21 & 11 \\
\hline Ankle swelling & 368 & 59 & 96 & 49 \\
\hline Third heart sound & 0 & & 0 & \\
\hline $\begin{array}{l}\text { Jugular venous } \\
\text { pressure }\end{array}$ & 6 & 1 & 6 & 3 \\
\hline
\end{tabular}


Auscultation of the heart and lungs, measurements of blood pressure and heart rate and recordings of the presence of ankle swelling were done usually in every study regions, regardless of the type of visit. Recordings of liver size were less usual. In all, evaluation of jugular venous pressure was recorded very seldom, and no recordings of the third heart sound were found. ECG recordings were done usually but NYHA-gradings was recorded only in $8 \%$ of cases and echocardiography had been carried out in $13 \%$. Chest X-ray examinations were also done rarely.

\section{DISCUSSION}

Heart failure is a clinical syndrome rather than a disease, and it is diagnosed on the basis of the patient's symptoms and clinical findings (1). Thus, regular follow-up of the symptoms and clinical findings is needed to be able to evaluate the prognosis of HF. The prognosis of HF is severe as up to half of the patients die within five years (8). In our series the relatively long disease history, together with the relatively high prevalence of HF suggest that in several cases true chronic HF did not exist (7).

The European Society of Cardiology has published guidelines for the diagnosis and assessment of HF to be used in clinical practice, epidemiological surveys and clinical trials (9). No reliable "gold standard" exists for the diagnosis of HF in primary health care (7). Easy fatigability, weakness and tachycardia, related to reduced cardiac output, dyspnoea, reflecting pulmonary congestion, and peripheral swelling, increased venous pressure and hepatomegaly, suggestive of systemic congestion, are characteristic signs of HF. Some factors, such as breathlessness, ankle swelling and fatigue are non-specific as regards HF, and may be difficult to interpret, particulary among the elderly, the obese and women (7). In a study carried out in eastern Finland, dyspnoea and fatigue were the most frequent symptoms in HF patients, while ankle swelling and pulmonary rates were the most frequently observed clinical signs (7).

Specific signs of HF, such as increased venous pressure and a third heart sound, may be difficult to observe. Cardiologists show a high level of agreement as regards detecting the presence of a third heart sound (10), but inter-observer agreement is less than 50\% among non-specialists (11), and probably even lower in clinical practice (9). Indeed, in the present study, the third heart sound was not detected at all and elevated jugular pressure was recognized only occasionally. However, these are among the main criteria of HF (8) and in patients with symptomatic HF elevated jugular venous pressure exists in $11 \%$ and the third heart sound in $25 \%$ (12), suggesting that these examinations were underused by the GPs in our study. Beyond the age of forty, the presence of a third heart sound usually indicates cardiac pathology and may be the earliest sign of left ventricular failure (13). Moreover, the presence of a third heart sound and elevated jugular venous pressure predict progression of HF, hospitalization and death as a result of HF (12).

There is concern that physicians are becoming less proficient at performing physical examination (12). They often have poor cardiac auscultatory skills and clinical examination is often replaced by laboratory investigations, such as ECHO, a factor that further tends to reduce clinical bedside experience $(9,14)$.
Nevertheless, ECHO should be routinely used for the optimal diagnosis of HF. The test is simple and safe (9) and according to the European study (6) physicians request ECHO in $45 \%$ of HF cases, but there was large variations between countries. The availability of ECHO was not good in Northern Finland at the time our study started and it had been carried out only in $13 \%$ of the cases of HF. In agreement with this, in a Swedish study ECHO had been carried out in $17 \%$ of cases (15). At present, availability of ECHO in Northern Finland is obviously better than eight years ago.

A normal ECG rarely exists in patients with HF. The presence of anterior Q-waves and a left bundle branch block in patients with ischaemic heart disease are good predictors of a decreased ejection fraction (16) and arrhythmia may be a causative or contributing factor in cases of HF. The significance of ECG abnormalities increases with co-existing clinical symptoms and signs of HF (9). The clinician should always examine the ECG in patients with apparently established HF (17) and according to an international European study primary-care physicians requested it in $92 \%$ of $\mathrm{HF}$ cases (6).

Cardiomegaly seen in chest X-rays is frequently absent in acute HF and in cases of diastolic dysfunction. In chronic HF, a cardiothoracic ratio of more than 0.50 and the presence of pulmonary venous congestion are useful indicators of abnormal cardiac function with a decreased ejection fraction and elevated left ventricular filling pressure (18). In the present study, the relative low incidence of chest X-ray examinations suggests that many patients were asymptomatic because of false positive diagnosis and therefore were not in need of chest X-ray examination. However, GPs may also have difficulties in the interpretation of chest $\mathrm{X}$-ray findings in regard to $\mathrm{HF}$, which may contribute to the frequency of chest X-ray examinations. In our study the follow up time was only two years and chest X-ray examinations may have been done before that. Admission to hospital in case of symptomatic visits may have reduced the frequency of laboratory and X-ray examinations in primary health care. In Europe, about $80 \%$ of primary health care physicians request chest radiography in patients with suspected HF (6).

Interestingly, the number of health centre contacts in connection with HF was much lower than that presented in a Swedish study, where there were as many as seven visits per year (15). In our study the incidence of visits and the examination practices were consistent in the three primary health care areas. The relevance of medical reports as a measure of actual examination practices is questionable, because normal clinical findings may not be recorded. Clearly, however, some clinical examinations of significant value in the assessment of the prognosis of HF patients are underused by GPs. In particular, evaluation of venous pressure specific for HF, and a third heart sound, are rarely used in their clinical practice. The prevalence of HF defined from the medical records of health centers greatly exceeds that presented in studies using strict criteria (3). Therefore, the false positive HF cases should critically medically evaluated in primary health care, as also previously indicated. Hence, further education is needed to improve this situation.

\section{Acknowledgements}

This study was supported by MSD Finland. 


\section{REFERENCES}

1. Tresch DD. Clinical manifestations, diagnostic assessment, and etiology of heart failure in elderly patients. Clin Geriatr Med. 2000 Aug;16(3):445-56.

2. Khunti K, Baker R, Grimshaw G. Diagnosis of patients with chronic heart failure in primary care: usefulness of history, examination, and investigations. Br J Gen Pract. 2000 Jan;50(450):50-4.

3. Cleland JG, Clark A. Has the survival of the heart failure population changed? Lessons from trials. Am J Cardiol. 1999 Mar 11;83(5B):112D-19D.

4. Cowie MR, Wood DA, Coats AJ, Thomson SG, Poole-Wilson PA. Incidence and aetiology of heart failure; a population-based study. Eur Heart J. 1999 Mar;20(6):421-8.

5. Remes J, Reunanen A, Aromaa A, Pyörälä K. Incidence of heart failure in eastern Finland: a population-based surveillance study. Eur Heart J. 1992 May;13(5):588-93.

6. Cleland JG, Cohen-Solal A, Aguilar JC, Dietz R, Eastaugh J, Follath F, et al. Management of heart failure in primary care (the IMPROVEMENT of Heart Failure Programme): an international survey. Lancet. 2002 Nov 23;360(9346):1631-9.

7. Remes J, Miettinen H, Reunanen A, Pyörälä K. Validity of clinical diagnosis of heart failure in primary health care. Eur Heart J. 1991 Mar;12(3):315-21.

8. McKee PA, Castelli WP, McNamara PM, Kannel WB. The natural history of congestive heart failure: the Framingham study. N Engl J Med. 1971 Dec 23;285(26):1441-6.

9. Remme WJ, Swedberg K; Task Force for the Diagnosis and Treatment of Chronic Heart Failure, European Society of Cardiology. Guidelines for the diagnosis and treatment of chronic heart failure. Eur Heart J. 2001 Sep;22(17):1527-60
10. Butman SM, Ewy GA, Standen JR, Kern KB, Hahn E. Bedside cardiovascular examination in patients with severe chronic heart failure: importance of rest or inducible jugular venous distension. J Am Coll Cardiol. 1993 Oct;22(4):968-74.

11. Ishmail AA, Wing S, Ferguson J, Hutchinson TA, Magder S, Flegel KM. Interobserver agreement by auscultation in the presence of a third heart sound in patients with congestive heart failure. Chest. 1987 Jun;91(6):870-3.

12. Drazner MH, Rame JE, Stevenson LW, Dries DL. Prognostic importance of elevated jugular venous pressure and a third heart sound in patients with heart failure. N Engl J Med. 2001 Aug 23;345(8):574-81.

13. Joshi N. The third heart sound. South Med J. 1999 Aug;92(8):756-61.

14. Adolph RJ. In defence of the stethoscope. Chest. 1998 Nov;114(5): 1235-7.

15. Nilsson G, Strender LE. Management of heart failure in primary health care. A retrospective study on electronic patient records in a registered population. Scand J Prim Health Care. 2002 Sep;20(3):161-5.

16. Wheeldon NM, MacDonald TM, Flucker CJ, McKendrick AD, McDevitt DG Struthers AD. Echocardiography in chronic heart failure in the community. Q J Med. 1993 Jan;86(1):17-23.

17. Kelly J, Kelleher K. The electrocardiogram in heart failure. Age Ageing. 2000 May;29(3):203-6.

18. Badgett RG, Lucey CR, Mulrow CD. Can the clinical examination diagnose left-sided heart failure in adults? JAMA. 1997 Jun 4;277(21):1712-9.

Received October 21, 2005 Received in revised form and accepted January 30, 2006 